\title{
Demographic and metabolic characteristics of individuals with progressive glucose tolerance
}

\author{
A.L. Mendes ${ }^{1}$, M.L. Santos ${ }^{1}$, C.R. Padovani ${ }^{2}$ and W.P. Pimenta ${ }^{1}$ \\ ${ }^{1}$ Departamento de Medicina Interna, Faculdade de Medicina de Botucatu, ${ }^{2}$ Departamento de \\ Bioestatística, Instituto de Biociências, Universidade Estadual Paulista, Botucatu, SP, Brasil \\ Correspondence to: W.P. Pimenta, Departamento de Clínica Médica, Faculdade de Medicina de \\ Botucatu, UNESP, 18618-970 Botucatu, SP, Brasil \\ Fax: +55-14-3882-2238. E-mail: wpimenta@fmb.unesp.br
}

\begin{abstract}
We evaluated changes in glucose tolerance of 17 progressors and 62 non-progressors for 9 years to improve our understanding of the pathogenesis of type 2 diabetes mellitus. Changes in anthropometric measurements and responses to an oral glucose tolerance test (OGTT) were analyzed. We identified 14 pairs of individuals, one from each group, who were initially normal glucose tolerant and were matched for gender, age, weight, and girth. We compared initial plasma glucose and insulin curves (from OGTT), insulin secretion (first and second phases) and insulin sensitivity indices (from hyperglycemic clamp assay) for both groups. In the normal glucose tolerant phase, progressors presented: 1) a higher OGTT blood glucose response with hyperglycemia in the second hour and a similar insulin response vs non-progressors; 2) a reduced first-phase insulin secretion $(2.0 \pm 0.3$ vs $2.3 \pm 0.3 \mathrm{pmol} / \mathrm{L} ; \mathrm{P}<0.02)$ with a similar insulin sensitivity index and a lower disposition index $(3.9 \pm 0.2$ vs $4.1 \pm$ $\left.0.2 \mu \mathrm{mol} \cdot \mathrm{kg}^{-1} \cdot \mathrm{min}^{-1} ; \mathrm{P}<0.05\right)$ vs non-progressors. After 9 years, both groups presented similar increases in weight and fasting blood glucose levels and progressors had an increased glycemic response at $120 \mathrm{~min}(\mathrm{P}<0.05)$ and reduced early insulin response to OGTT (progressors, $1 \mathrm{st}: 2.10 \pm 0.34 \mathrm{vs} 2 \mathrm{nd}: 1.87 \pm 0.25 \mathrm{pmol} / \mathrm{mmol}$; non-progressors, $1 \mathrm{st}: 2.15 \pm 0.28 \mathrm{vs} 2 \mathrm{nd}$ : 2.03 $\pm 0.39 \mathrm{pmol} / \mathrm{mmol} ; \mathrm{P}<0.05)$. Theses data suggest that $\beta$-cell dysfunction might be a risk factor for type 2 diabetes mellitus.
\end{abstract}

Key words: Impaired glucose tolerance; Impaired insulin secretion; Normal glucose tolerance; Hyperglycemic clamp; Oral glucose tolerance test

Research supported by FAPESP (\#04/13057-1).

Received January 19, 2008. Accepted January 26, 2009

\section{Introduction}

Type 2 diabetes mellitus is a heterogeneous chronic metabolic syndrome caused by a deficiency in insulin secretion and resistance to insulin $(1,2)$. Approximately 200 million people suffer from diabetes worldwide; however, only about half are diagnosed. These numbers are expected to double by the year 2030 (2). Type 2 diabetes mellitus comprises $85-90 \%$ of diabetes cases and is an important public health problem of increasing magnitude due to aging populations, the increasing prevalence of obesity, and the decreasing age of onset of obesity (1).

To improve treatment for and prevent development of type 2 diabetes mellitus, we must improve our understanding of the physiopathological and molecular events that influence the progression of this disease (1). Increasing evidence supports the hypotheses that the fundamental pathological sequence of events that determines the development of type 2 diabetes mellitus is the superimposition of one or more factors that cause insulin resistance of $\beta$ cells that have a genetically limited compensation capacity (1). Prospective and longitudinal studies have been instrumental in elucidating details about the pathogenesis of type 2 diabetes mellitus. For example, the research of Weyer et al. (3), which focused on Pima Indians, and other population studies in various ethnic groups (4-6) have 
shown that glucose tolerance deterioration is due to the inability of $\beta$ cells to compensate for existing insulin resistance.

For the past 9 years, we have been comparing Brazilian white-complexioned individuals with and without firstgeneration relatives who have type 2 diabetes mellitus (7). We pair-matched individuals from each group with respect to gender, age, body mass index (BMI), and waist/hip ratio $(\mathrm{W} / \mathrm{H})$. Individuals were submitted to oral glucose tolerance test (OGTT) and 56 pairs with normal glucose tolerance (NGT) were identified. First- and second-phase insulin secretion and peripheral insulin sensitivity were analyzed by the hyperglycemic clamp technique. No differences between groups were found, contradicting results from a similar study of Caucasian North Americans with relatives who had insulin secretion deficiency (8). The difference in outcomes between these studies could have been due to the younger age and specific ethnic characteristics of the Brazilian individuals.

In the present study, our objective was to re-evaluate the glucose metabolism of progressor individuals compared with non-progressors for glucose tolerance. Progressors are those who evolved from NGT to impaired glucose tolerance (IGT) or type 2 diabetes mellitus, or from IGT to type 2 diabetes mellitus, during a 9-year interval. Progressors with NGT at first evaluation were true prediabetics and we hypothesized that re-evaluating their glucose metabolism over time might uncover risk factors for the development of type 2 diabetes mellitus.

\section{Subjects and Methods}

\section{Inclusion criteria and study design}

After approval from Research Ethics Committee of the Universidade Estadual Paulista, participants from our first study (7) who had NGT or IGT ( $=130)$ were invited to participate in a re-evaluation of their glucose tolerance. Inclusion criteria were: 1) willingness to participate and providing written informed consent; 2) good health status; 3) not using any medication that could interfere with glucose metabolism; 4) non-pregnancy for women of childbearing age. Seventy-nine individuals fulfilled the inclusion criteria. Non-participants did not differ from participants in demographic or metabolic characteristics (data not shown).

Participants arrived at the laboratory at $7 \mathrm{~h}$, having observed a 10- to 12-h overnight fast. For the preceding 3 days, their diet had contained at least $250 \mathrm{~g}$ carbohydrate per day. Clinical evaluation included: a) medical history, including reports of new occurrences of type 2 diabetes mellitus within their family and changes in lifestyle be- tween the first and current evaluations; b) physical examination with special attention to anthropometric and arterial pressure measurements. Blood and urine samples were collected for measuring glucose, glycosylated hemoglobin $\left(\mathrm{HbA}_{1 \mathrm{c}}\right)$, lipid profile, electrolytes, uric acid, renal and liver function tests, thyroid-stimulating hormone, free $T_{4}$, hemogram, and urine type I. Participants were then submitted to OGTT according to the Expert Committee on the Diagnosis and Classification of Diabetes Mellitus (1997) (9). In short, after providing a sample of basal blood, the participants ingested a 75-g load of glucose followed by blood sampling every $30 \mathrm{~min}$ for $2 \mathrm{~h}$ to measure glucose and insulin levels.

Participants were divided into two groups according to OGTT results: progressors ( $\mathrm{N}=17 ; 21.5 \%$ ): those with NGT or IGT at first evaluation who developed IGT ( $N=11 ; 64.7 \%)$ or type 2 diabetes mellitus ( $\mathrm{N}=3 ; 17.6 \%)$, respectively, and those with type 2 diabetes mellitus ( $\mathrm{N}=3$; 17.6\%); nonprogressors ( $\mathrm{N}=62 ; 78.5 \%$ ): those with NGT or IGT at first evaluation who maintained NGT ( $N=55 ; 88.7 \%)$, IGT ( $N=4$; $6.5 \%)$, or returned to NGT from IGT ( $N=3 ; 4.8 \%)$. A first analysis compared the two groups at the time they were first evaluated (about 9 years previously). We only considered individuals who were NGT at the initial evaluation and who were individually paired for gender, age, BMI, and waist circumference, obtaining 14 pairs. We compared demographic, OGTT, and hyperglycemic clamp variables according to the previous study (7). A second analysis encompassed all progressor $(\mathrm{N}=17)$ and non-progressor $(\mathrm{N}=62)$ participants. We compared the groups for changes in anthropometric measurements and OGTT variables over the 9 -year interval since the initial evaluation.

Briefly, using plasma glucose and insulin curves obtained from OGTT, we calculated: 1) the insulinogenic index as the ratio between the increase in plasma insulin and glucose in the first $30 \mathrm{~min}$, considered to be the expression of early phase insulin secretion $(10)$; 2) the area under the curve (AUC) for plasma glucose and insulin by the trapezoidal rule (11), considering the total area $\left(\mathrm{AUC}_{\mathrm{t}}\right)$ from 0 to $120 \mathrm{~min}$. The hyperglycemic clamp procedure $(7,8)$ allowed calculation of: 1) first-phase insulin secretion as the sum of plasma insulin concentrations (sum) or as its highest value (peak) in the first $10 \mathrm{~min}$; 2) second-phase insulin secretion as the mean plasma insulin concentration during the third hour; 3) insulin sensitivity index, as the ratio between mean glucose infusion rate during the third hour and second-phase insulin secretion, which has been shown to have excellent correlation with the same parameter obtained by euglycemic/hyperinsulinemic clamp $(8,12) ; 4)$ disposition index, as the first-phase insulin secretion as a function of insulin sensitivity index (13). 
Data collection and analysis

An anthropometric balance (Filizzola ${ }^{\circledR}$, Brazil) and tape measure were used for body measurements and the auscultatory method was used to measure arterial pressure. Biochemical measurements were made by multichannel analyzer (Ortho Clinical Diagnosis, Johnson \& Johnson, USA). $\mathrm{HbA}_{1 \mathrm{C}}$ was measured by ion exchange chromatography (Labtest, Brazil; $\mathrm{N}$ : 4.2-6.4\%); plasma glucose was determined by the glucose oxidase method (Beckman Instruments, USA); plasma insulin was measured by solid phase radioimmunoassay (Diagnostic Products Corporation, USA), with intra- and inter-assay errors of $5-10 \%$.

Comparisons between groups in the transverse study were analyzed by Student $t$ - and Mann-Whitney tests for parametric (mean \pm standard deviation, SD) and non-parametric variables (median \pm interquartile semi-amplitude), respectively (11). In the prospective study, comparisons were made by repeated measures analysis of variance, except for basal clinical and biochemical parameter variations, where Student $t$ - or Mann-Whitney tests were used (11). Differences were considered to be significant when $\mathrm{P}<0.05$.

\section{Results}

Both groups (17 progressors and 62 nonprogressors) reported that they had not modified their eating habits or lifestyles and had not developed any relevant illnesses during the 9-year interval. However, some relatives of participants had developed type 2 diabetes mellitus.

Initial demographic and metabolic characteristics of paired participants (14 pairs)

The main clinical and basal laboratory characteristics of the 14 pairs from the two groups (progressors and non-progressors) are reported in Table 1. Progressors had a higher frequency of relatives with type 2 diabetes mellitus and a higher $\mathrm{W} / \mathrm{H}$ ratio; all other variables were similar between the two groups.

Second hour OGTT plasma glucose and $\mathrm{AUC}_{\mathrm{t}}$ for plasma glucose values were significantly higher in the progressor group than in the non-progressor group (Figure 1). However, the plasma insulin curves and their respective $A \cup C_{t}$ did not differ between groups (Figure 1). There were also no differences between groups for the ratio between the plasma insulin $\mathrm{AUC}_{\mathrm{t}}$ and the plasma glucose $A \cup C_{t}(0.90 \pm$ 0.02 vs $0.90 \pm 0.03 \mathrm{pmol} / \mathrm{mmol} ; \mathrm{P}>0.05$ ) or the insulinogenic index (Figure 1).

For the hyperglycemic clamp assay, first-phase insulin secretion, sum and peak were significantly lower in the progressor group, but there were no significant differences between groups for second-phase secretion or insulin sensitivity index (Table 2). For each level of insulin sensitivity, progressors responded with less insulin secretion than did non-progressors (Figure 2).

\section{Evolution of demographic and metabolic characteristics} of 17 progressors and 62 non-progressors

Both groups presented similar increases in weight and central adiposity measurements over the 9-year interval (Table 3). Diastolic arterial pressure did not change in either group; systolic arterial pressure increased in the non-progressor group only, although it stayed within normal limits (Table 3). Fasting blood glucose increased significantly in both groups and was significantly higher in the progressor group than in the non-progressor group (Table $3)$. Both groups also had a similar increase in $\mathrm{HbA}_{1 \mathrm{C}}$ associated with this blood glucose change (Table 3 ). However, fasting plasma insulin was unchanged in both groups (Table 3). Both groups showed a similar significant increase in serum triglycerides (Table 3 ).

Table 1. Baseline clinical and laboratory characteristics of individuals with progressor or non-progressor glucose tolerance status.

\begin{tabular}{|c|c|c|}
\hline Characteristics & $\begin{array}{l}\text { Progressors } \\
\quad(N=14)\end{array}$ & $\begin{array}{c}\text { Non-progressors } \\
(\mathrm{N}=14)\end{array}$ \\
\hline Gender (female/male) & $14 / 0$ & $14 / 0$ \\
\hline Time interval (months) ${ }^{a}$ & $104 \pm 22$ & $113 \pm 3$ \\
\hline Age (years) ${ }^{a}$ & $33 \pm 5$ & $34 \pm 6$ \\
\hline Number of pregnancies & $2 \pm 1$ & $3 \pm 1$ \\
\hline Smoking (\%) & 57 & 36 \\
\hline Family history of T2DM (\%) & 71 & $36^{*}$ \\
\hline $\mathrm{BMI}\left(\mathrm{kg} / \mathrm{m}^{2}\right)$ & $25.6 \pm 2.4$ & $25.9 \pm 3.9$ \\
\hline Girth $(\mathrm{cm})$ & $81.4 \pm 6.6$ & $80.8 \pm 5.6$ \\
\hline $\mathrm{W} / \mathrm{H}$ ratio & $0.82 \pm 0.04$ & $0.79 \pm 0.03^{*}$ \\
\hline Systolic arterial pressure $(\mathrm{mmHg})^{\mathrm{a}}$ & $108 \pm 5$ & $100 \pm 8$ \\
\hline Diastolic arterial pressure $(\mathrm{mmHg})^{a}$ & $70 \pm 5$ & $70 \pm 8$ \\
\hline Fasting plasma glucose $(\mathrm{mmol} / \mathrm{L})$ & $5.0 \pm 0.6$ & $4.7 \pm 0.6$ \\
\hline Fasting plasma insulin $(\mathrm{pmol} / \mathrm{L})^{\mathrm{b}}$ & $1.86 \pm 0.24$ & $1.76 \pm 0.25$ \\
\hline $\mathrm{HbA}_{1 \mathrm{c}}(\%)$ & $5.3 \pm 0.5$ & $5.0 \pm 0.5$ \\
\hline Serum TC minus HDL-C (mg/dL) & $147 \pm 32$ & $148 \pm 60$ \\
\hline Serum HDL-C $(\mathrm{mg} / \mathrm{dL})$ & $44 \pm 30$ & $35 \pm 8$ \\
\hline Serum triglycerides $(\mathrm{mg} / \mathrm{dL})$ & $117 \pm 47$ & $116 \pm 60$ \\
\hline
\end{tabular}

Data are reported as means $\pm S D$, unless otherwise indicated. aMedian \pm interquartile semi-amplitude; b data with logarithmic transformation; T2DM = type 2 diabetes mellitus; $\mathrm{BMI}=$ body mass index; $\mathrm{W} / \mathrm{H}=$ waist hip; $\mathrm{HbA}_{1 \mathrm{c}}=$ glycosylated hemoglobin; $\mathrm{TC}=$ total cholesterol; $\mathrm{HDL}-\mathrm{C}=$ highdensity cholesterol. ${ }^{*} \mathrm{P}<0.05$ compared to individuals with progressor glucose tolerance status (Student $t-$, Mann-Whitney and Goodmann tests). 

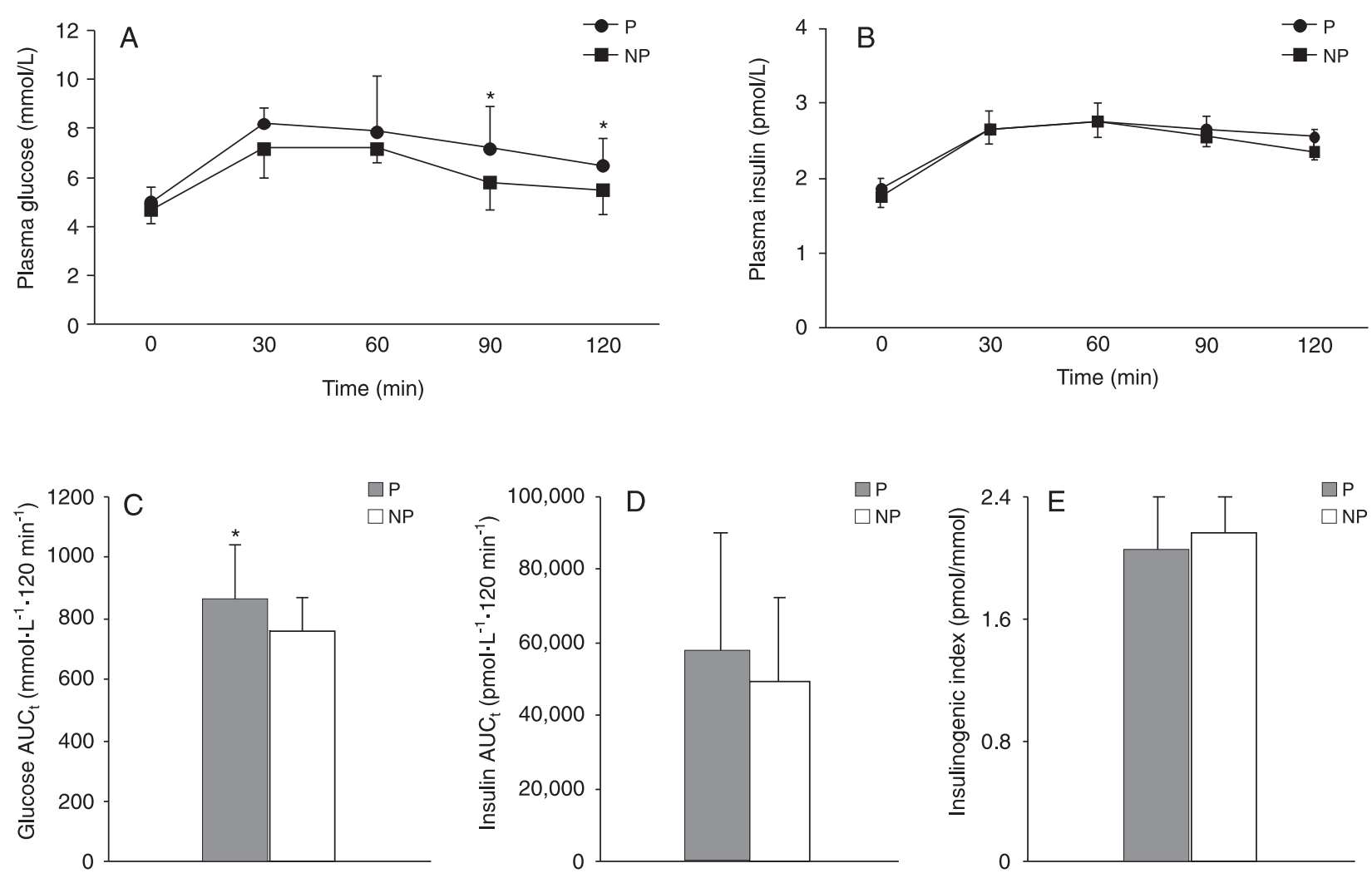

Figure 1. Oral glucose tolerance test performed 9 years previous in progressor $(P)$ and non-progressor (NP) groups. Plasma glucose $(A)$ and insulin curves $(B)$; total area under curve $\left(A \cup C_{t}\right)$ of plasma glucose $(C)$ and insulin $(D)$; insulinogenic index $(E)$ are reported. Data are reported as means \pm SD and represent log transformations of insulin values. ${ }^{*} \mathrm{P}<0.05$ compared to NP (Student $t$-test).

Table 2. Baseline hyperglycemic clamp parameters of individuals with progressor or non-progressor glucose tolerance status.

\begin{tabular}{lcc}
\hline Hyperglycemic clamp & $\begin{array}{c}\text { Progressors } \\
(\mathrm{N}=14)\end{array}$ & $\begin{array}{c}\text { Non-progressors } \\
(\mathrm{N}=14)\end{array}$ \\
\hline $\begin{array}{l}\text { First-phase insulin secretion } \\
\quad \text { sum }(\mathrm{pmol} / \mathrm{L})\end{array}$ & $2.9 \pm 0.1$ & $3.2 \pm 0.1^{*}$ \\
$\begin{array}{l}\text { First-phase insulin secretion } \\
\text { peak }(\mathrm{pmol} / \mathrm{L})\end{array}$ & $1.5 \pm 0.3$ & $1.8 \pm 0.3^{*}$ \\
$\begin{array}{l}\text { Second-phase insulin secretion } \\
\quad(\mathrm{pmol} / \mathrm{L})\end{array}$ & $2.5 \pm 0.1$ & $2.7 \pm 0.1$ \\
$\begin{array}{l}\text { Glucose infusion rate } \\
\quad\left(\mu \mathrm{mol} \cdot \mathrm{kg}^{-1} \cdot \mathrm{min}^{-1}\right)\end{array}$ & $40.6 \pm 3.8$ & $52.0 \pm 3.7^{*}$ \\
$\begin{array}{l}\text { Insulin sensitivity index } \\
\left(\mu \mathrm{mol} \cdot \mathrm{kg}^{-1} \cdot \mathrm{min}^{-1} / \mathrm{pmol} \cdot \mathrm{L}^{-1}\right)\end{array}$ & $13.2 \pm 2.0$ & $11.1 \pm 1.8$ \\
$\begin{array}{l}\text { Disposition index } \\
\left(\mu \mathrm{mol} \cdot \mathrm{kg}^{-1} \cdot \mathrm{min}^{-1}\right)\end{array}$ & $3.9 \pm 0.2$ & $4.1 \pm 0.2^{*}$ \\
& &
\end{tabular}

Data are reported as means \pm SEM. Insulin values were obtained after log transformation, except for the insulin sensitivity index. ${ }^{*} \mathrm{P}<0.05$ compared to individuals with progressor glucose tolerance status (Student $t$ - and Mann-Whitney tests).

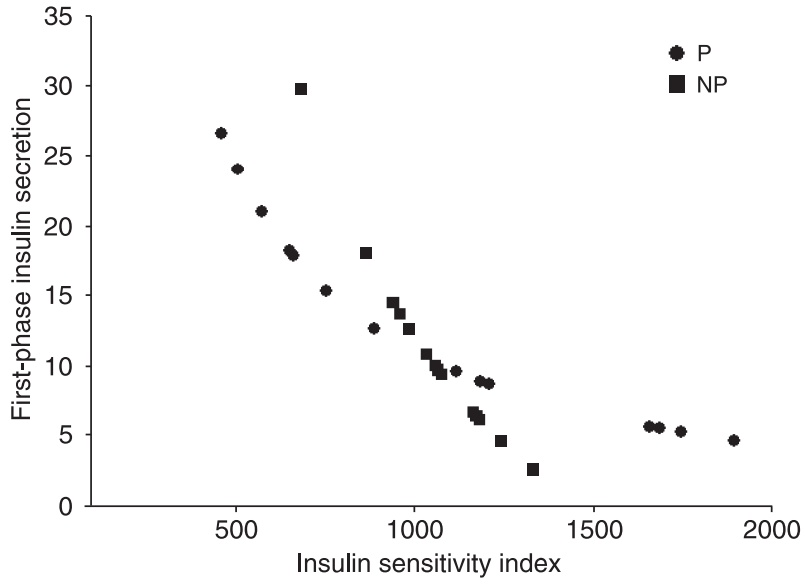

Figure 2. Hyperglycemic clamp performed about 9 years previous in progressor $(\mathrm{P})$ and non-progressor (NP) groups: disposition index (first-phase insulin secretion $v s$ insulin sensitivity index). 
Table 3. Clinical and basal laboratory characteristics of individuals with progressor or non-progressor glucose tolerance status.

\begin{tabular}{|c|c|c|}
\hline Characteristic & Progressors $(\mathrm{N}=17)$ & Non-progressors $(\mathrm{N}=62)$ \\
\hline Gender (female/male) & $17 / 0$ & $58 / 4$ \\
\hline \multicolumn{3}{|l|}{ Age (years) } \\
\hline 1st evaluation & $34 \pm 7^{A}$ & $37 \pm 7^{A}$ \\
\hline 2nd evaluation & $41 \pm 8^{B}$ & $45 \pm 7^{B}$ \\
\hline$\Delta$ (years) & $8 \pm 3$ & $9 \pm 1$ \\
\hline \multicolumn{3}{|l|}{ BMI $\left(\mathrm{kg} / \mathrm{m}^{2}\right)$} \\
\hline 1st evaluation & $25.8 \pm 2.3^{\mathrm{A}}$ & $25.8 \pm 3.3^{\mathrm{A}}$ \\
\hline 2nd evaluation & $27.9 \pm 3.0^{B}$ & $27.2 \pm 3.3^{B}$ \\
\hline$\Delta\left(\mathrm{kg} / \mathrm{m}^{2}\right)$ & $2.0 \pm 1.5$ & $2.0 \pm 1.0$ \\
\hline \multicolumn{3}{|l|}{ Girth $(\mathrm{cm})$} \\
\hline 1st evaluation & $81.7 \pm 6.3^{\mathrm{A}}$ & $79.6 \pm 8.9^{A}$ \\
\hline 2nd evaluation & $84.5 \pm 7.2^{\mathrm{B}}$ & $81.9 \pm 8.0^{\mathrm{B}}$ \\
\hline$\Delta(\mathrm{cm})$ & $1.5 \pm 3.0$ & $3.0 \pm 2.0$ \\
\hline \multicolumn{3}{|l|}{$\mathrm{W} / \mathrm{H}$ ratio } \\
\hline 1st evaluation & $0.82 \pm 0.04^{\mathrm{A}}$ & $0.79 \pm 0.05^{\mathrm{A}}$ \\
\hline 2nd evaluation & $0.84 \pm 0.05^{\mathrm{B}}$ & $0.82 \pm 0.05^{\mathrm{B}}$ \\
\hline$\Delta$ & $0.01 \pm 0.03$ & $0.03 \pm 0.02$ \\
\hline \multicolumn{3}{|c|}{ Systolic arterial pressure $(\mathrm{mmHg})$} \\
\hline 1st evaluation & $107 \pm 11^{A}$ & $106 \pm 13^{A}$ \\
\hline 2nd evaluation & $112 \pm 13^{\mathrm{A}}$ & $112 \pm 16^{\mathrm{B}}$ \\
\hline$\Delta(\mathrm{mmHg})$ & $10 \pm 8$ & $10 \pm 9$ \\
\hline \multicolumn{3}{|c|}{ Diastolic arterial pressure $(\mathrm{mmHg})$} \\
\hline 1st evaluation & $71 \pm 8^{\mathrm{A}}$ & $72 \pm 9^{A}$ \\
\hline 2nd evaluation & $75 \pm 13^{A}$ & $71 \pm 11^{A}$ \\
\hline$\Delta(\mathrm{mmHg})$ & $10 \pm 8$ & $10 \pm 5$ \\
\hline \multicolumn{3}{|c|}{ Fasting plasma glucose (mmol/L) } \\
\hline 1st evaluation & $5.2 \pm 0.6^{\mathrm{A}}$ & $4.8 \pm 0.6^{\mathrm{A}}$ \\
\hline 2nd evaluation & $5.7 \pm 0.9^{B}$ & $5.1 \pm 0.7^{B}$ \\
\hline$\Delta(\mathrm{mmol} / \mathrm{L})$ & $0.9 \pm 1.0$ & $0.4 \pm 0.7^{*}$ \\
\hline \multicolumn{3}{|c|}{ Fasting plasma insulin (pmol/L) } \\
\hline 1st evaluation & $71 \pm 38^{A}$ & $64 \pm 54^{A}$ \\
\hline 2nd evaluation & $83 \pm 57^{A}$ & $55 \pm 36^{A}$ \\
\hline$\Delta(\%)$ & $10.2 \pm 0.7$ & $8.3 \pm 0.5$ \\
\hline \multicolumn{3}{|l|}{$\mathrm{HbA}_{1 \mathrm{C}}(\%)$} \\
\hline 1st evaluation & $5.2 \pm 0.5^{\mathrm{A}}$ & $5.1 \pm 0.5^{\mathrm{A}}$ \\
\hline 2nd evaluation & $5.7 \pm 0.6^{\mathrm{B}}$ & $5.6 \pm 1.1^{B}$ \\
\hline$\Delta(\%)$ & $10.7 \pm 0.1$ & $11.0 \pm 0.2$ \\
\hline \multicolumn{3}{|c|}{ Serum TC minus HDL-C (mg/dL) } \\
\hline 1st evaluation & $129 \pm 32^{A}$ & $141 \pm 37^{A}$ \\
\hline 2nd evaluation & $135 \pm 19^{\mathrm{A}}$ & $134 \pm 41^{A}$ \\
\hline$\Delta(\%)$ & $10.2 \pm 0.2$ & $10.0 \pm 0.3$ \\
\hline \multicolumn{3}{|l|}{ Serum HDL-C (mg/dL) } \\
\hline 1st evaluation & $44 \pm 27^{A}$ & $38 \pm 9 A$ \\
\hline 2nd evaluation & $43 \pm 10^{\mathrm{A}}$ & $50 \pm 14^{\mathrm{B}}$ \\
\hline$\Delta(\%)$ & $10.3 \pm 0.2$ & $12.9 \pm 0.4^{*}$ \\
\hline \multicolumn{3}{|c|}{ Serum triglycerides $(\mathrm{mmHg})$} \\
\hline 1 st evaluation & $125 \pm 48^{A}$ & $95 \pm 44^{\mathrm{A}}$ \\
\hline 2nd evaluation & $162 \pm 81^{B}$ & $130 \pm 71^{B}$ \\
\hline$\Delta(\%)$ & $12.8 \pm 0.7$ & $13.8 \pm 0.7$ \\
\hline
\end{tabular}

Data are reported as means $\pm \mathrm{SD}$, unless otherwise indicated. $\mathrm{BMI}=$ body mass index; $\mathrm{W} / \mathrm{H}=$ waist hip; $\mathrm{HbA}_{1 \mathrm{C}}=$ glycated hemoglobin; $\mathrm{TC}=$ total cholesterol; HDL-C = high-density lipoprotein cholesterol. 1st evaluation = about 9 years previous; 2 nd evaluation $=$ current. Different superscript letters indicate statistically significant differences between 1 st and 2 nd evaluations $\left(P<0.05\right.$, RMANOVA). ${ }^{*} P<0.05$ compared to individuals with progressor glucose tolerance status (Student $t$-test). 
The blood glucose curve in response to oral glucose challenge did not change over the 9-year interval for the non-progressor group, but increased significantly in the progressor group (Figure 3). Blood glucose values were significantly higher in the progressor group than in the nonprogressor group at both evaluations (Figure 3). The insulinemia curve after oral glucose load did not change in either group (Figure 3). However, in real time, plasma insulin values in the second hour of OGTT were significantly higher and the peak much later, $90 \mathrm{~min}$ instead of $60 \mathrm{~min}$, in the progressor group (Figure 3). Consequently, the plasma glucose $A \cup C_{t}$ value increased significantly with
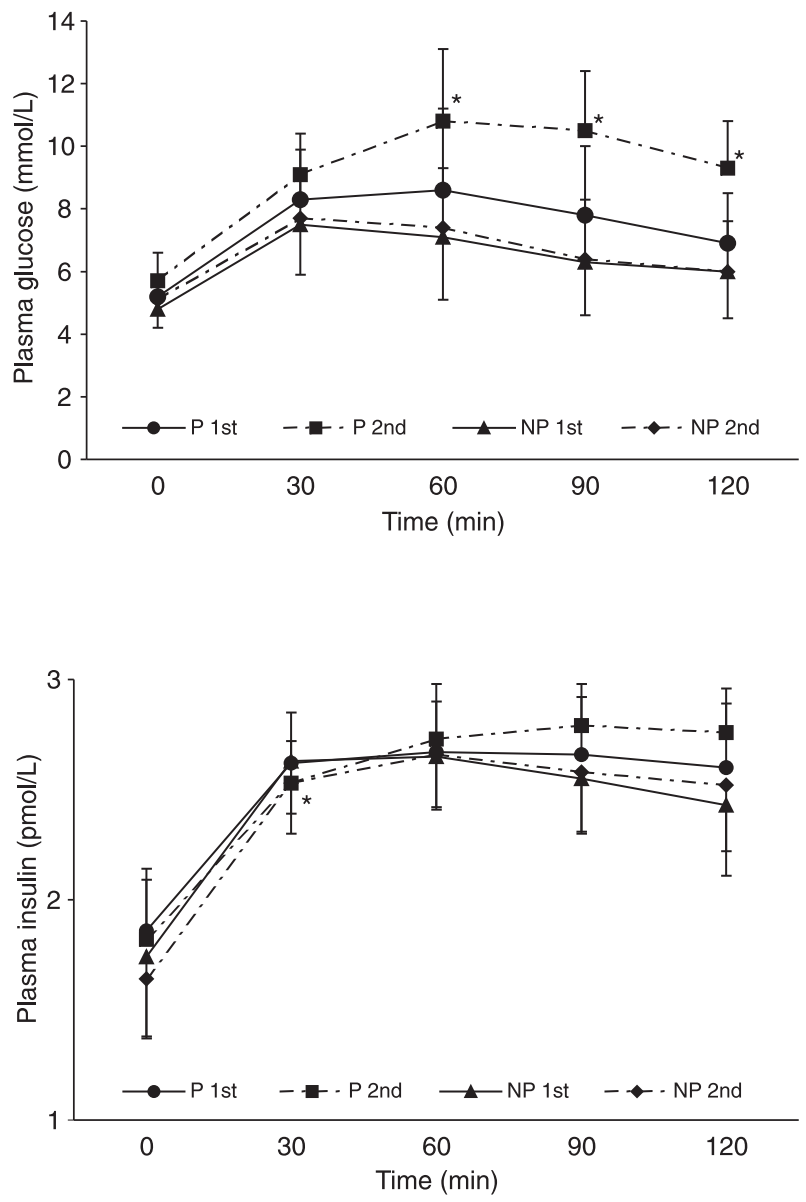

Figure 3. Oral glucose tolerance test: plasma glucose and insulin curves for progressor $(\mathrm{P})$ and non-progressor (NP) groups according to time of evaluation: $1 \mathrm{st}$, about 9 years previous; 2 nd, current. Data are reported as means \pm SD and represent log transformations of insulin values. ${ }^{*} P<0.05$ compared to first and second evaluations (Mann-Whitney test). time for the progressor group only (Figure 4) and was higher than the $\mathrm{AUC}_{\mathrm{t}}$ value for the non-progressor group. However, plasma insulin $A \cup C_{t}$ values did not change, remaining similar in both groups (Figure 4). Over the 9year interval, the insulinogenic index decreased significantly in the progressor group (Figure 4).
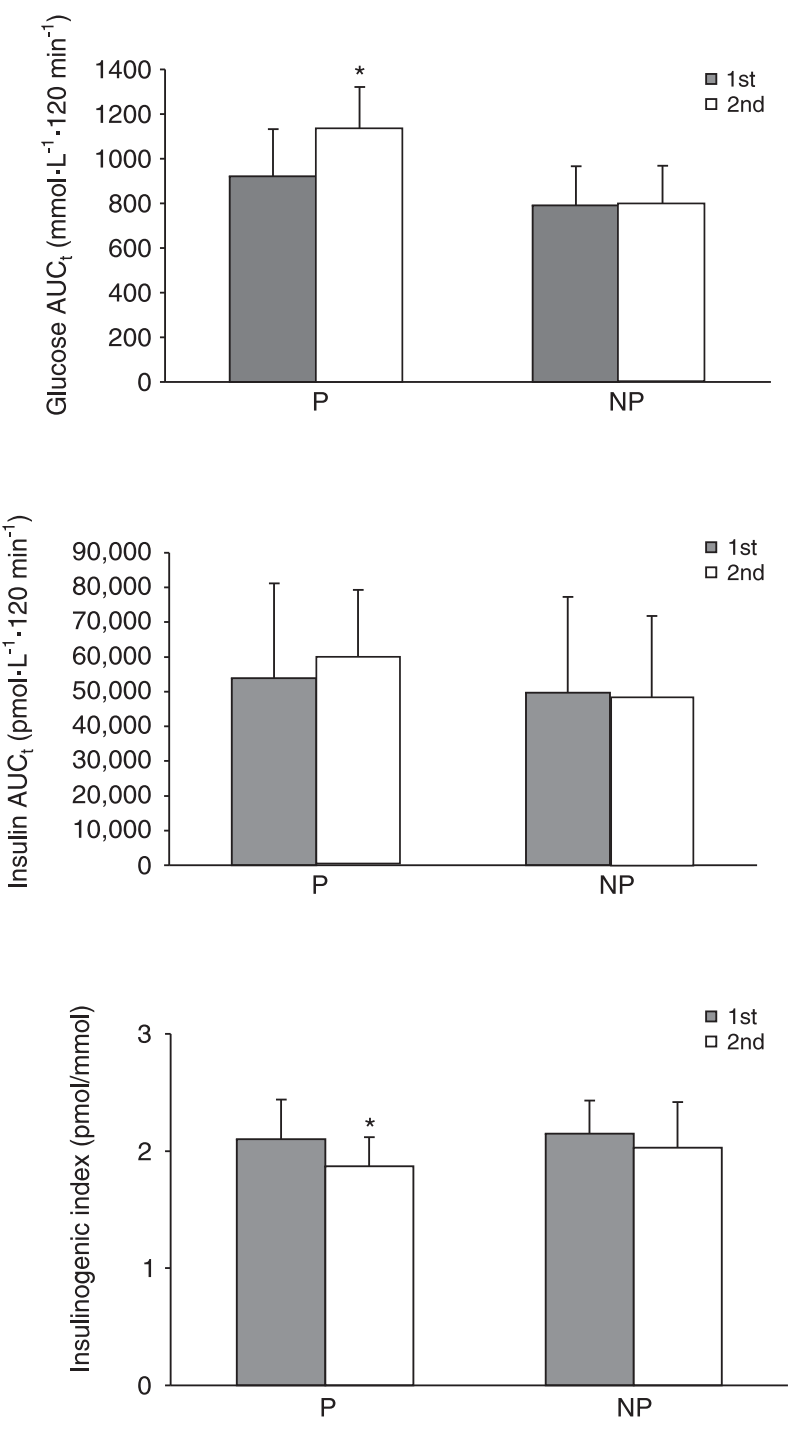

Figure 4. Oral glucose tolerance test: total areas under the curve $\left(A \cup C_{t}\right)$ of plasma glucose and insulin; insulinogenic index for progressor (P) and non-progressor (NP) groups, according to time of evaluation: 1st, about 9 years previous; 2 nd, current. Data are reported as means \pm SD and represent log transformations of insulin values. ${ }^{*} \mathrm{P}<0.05$ compared to first and second evaluations (Mann-Whitney test). 


\section{Discussion}

The results of the transversal and prospective analysis supported the opinion that $\beta$ cell dysfunction is the primary defect of type 2 diabetes mellitus.

During the 9-year period, 17 of 79 individuals (21.5\%) evolved from NGT to IGT or from IGT to type 2 diabetes mellitus. Most of these $17(\mathrm{~N}=14)$ were NGT at the first evaluation and were therefore pre-diabetic. Comparing glucose metabolism characteristics of the individuals in this phase with those of the non-progressors can help to identify risk factors for developing type 2 diabetes mellitus that could be targeted for preventing or postponing disease onset (14).

Comparative analysis of initial demographic and metabolic characteristics for paired progressors and non-progressors

We identified 14 pairs of initially NGT individuals, one progressor and 1 non-progressor, matched for main insulin resistance determining factors (15). Even though the progressor group had a significantly higher $\mathrm{W} / \mathrm{H}$ ratio than the non-progressor group, the $\mathrm{W} / \mathrm{H}$ ratio for the progressor group was only a little above normal. Interestingly, Bonora et al. (16) found that women's waist circumference value, which was similar to that found in our study, and age were related to visceral fat and that the $\mathrm{W} / \mathrm{H}$ ratio was a good index of the relationship between central and peripheral fat. Therefore, the composition of our study group seems adequate for comparatively evaluating glucose metabolism for pre-diabetic and control individuals.

It is well established that type 2 diabetes mellitus results from the interplay between genetic and environmental factors (17). This was reinforced by the characteristics of the progressor group who presented a higher frequency of type 2 diabetes mellitus family history. The progressor group did not differ from the non-progressor group regarding glucose metabolism at baseline (plasma glucose, insulin, and $\mathrm{HbA}_{1 \mathrm{c}}$ ), and therefore was free from the effects of glucotoxicity on insulin secretion and action (1). This result differs from that of population studies in lowincome Mexicans (5) and Fins from the Botnia Study (6), which showed that progressors initially present increased basal glucose and insulin levels. An intermediate result was reported by Xiang et al. (18) in their non-population study of Hispanic women with a recent history of gestational diabetes mellitus, where progressors initially presented elevated fasting blood glucose but fasting insulinemia similar to non-progressors.

Ingesting $75 \mathrm{~g}$ glucose led to a much higher blood glucose response by progressor individuals, mainly in the second hour after ingestion. This increased blood glucose response was not accompanied by an increased response from pancreatic $\beta$ cells. These data are representative of one of the early $\beta$ cell functional defects in type 2 diabetes mellitus $(19,20)$, which could have been occurring in progressors, and suggest that insulin secretion in response to an oral glucose challenge is reduced in progressors who are still in the NGT phase.

Elevated blood glucose $2 \mathrm{~h}$ after an oral glucose load or an equivalently elevated postprandial blood glucose represents a defect that generally precedes increased fasting blood glucose in the evolution from NGT to type 2 diabetes mellitus (21). Supporting this observation, elevated blood glucose 120 min after ingesting $75 \mathrm{~g}$ glucose was one of the parameters predictive of evolution to glucose intolerance in longitudinal studies in different population groups: Pima Indians (22), Fins (23), low-income Mexicans (5), and Canadians (24).

Clinical $(12,17,25,26)$ or experimental $(27)$ results in humans have shown that a reduction in first-phase insulin secretion is a determinant of hyperglycemia $2 \mathrm{~h}$ after an oral glucose dose or a mixed meal. This is because the first-phase insulin response is responsible for efficiently changing the metabolic state from glucose production (fasting) to glucose consumption (postprandial) (10). Our finding of elevated blood glucose in the second hour of the OGTT can be explained by the reduction in first-phase insulin secretion in the hyperglycemic clamp test. Previous studies $(3,18,28-31)$, including ours involving Caucasian Americans (8), have reported that individuals with NGT and at risk for type 2 diabetes mellitus have an insufficient insulin response to intravenous glucose stimulation tests, suggesting that $\beta$ cell dysfunction could be the first defect involved in type 2 diabetes mellitus pathogenesis.

The response from $\beta$ cells in the first 30 min following glucose challenge or the insulinogenic index is considered to be an expression of first-phase insulin secretion (10). However, this parameter did not differ between progressor and non-progressor groups, possibly due to the lower sensitivity of oral versus intravenous glucose stimulation for demonstrating $\beta$ cell function disorders and/or the small number of pairs in our study. Actually, in population studies of different ethnic groups, a reduced insulinogenic index was predictive of NGT evolving to type 2 diabetes mellitus (1). We must emphasize that in this initial glucose tolerance evolution phase, progressors had insulin sensitivity similar to that of non-progressors, which agrees with most studies in first-generation relatives of persons with type 2 diabetes mellitus, when those with NGT were well-paired with controls for parameters known to interfere with insulin sensitivity (17). 
The reduction in disposition index presented by the progressor group was of fundamental importance. For each insulin sensitivity index level in the progressor group, relative to the non-progressor group, there was a reduced response capacity from pancreatic $\beta$ cells. This deficiency was the strongest metabolic predictor of the evolution to type 2 diabetes mellitus in Pima Indians (3), Fins in the Botnia Study (6), and Hispanic women with a recent history of gestational diabetes mellitus (18).

Comparative analysis of demographic and metabolic characteristics for progressors vs non-progressors

The $\beta$ cell dysfunction and consequent hyperglycemia without concomitant reduction in insulin sensitivity, as seen in the NGT phase of our progressors, suggests that $\beta$ cell dysfunction was the primary defect contributing to the development of type 2 diabetes mellitus in these individuals. This observation is supported by the fact that this phenomenon worsened over time, unaccompanied by weight gain or an increase in central adiposity compared with the non-progressor group.

Body weight frequently increases with age, as do measurements indicative of abdominal fat (waist circumference and $\mathrm{W} / \mathrm{H}$ ratio). However, both groups experienced similar changes in this regard. Abdominal fat is more resistant to insulin than is peripheral fat, which leads to increased lipolysis and elevated circulating triglycerides. We found that both groups experienced similar elevations in circulating triglycerides over the 9-year interval. Individuals from both groups remained normotensive, and the blood pressures of individuals in the progressor group remained the same. Therefore, in this study, worsening glucose tolerance did not result from $\beta$ cell function overload. It is more likely that glucose tolerance declined due to intrinsic defects in these cells.

Large longitudinal studies of different ethnic groups have established that aging causes an increase in insulin resistance as the result of different factors, mainly from increased body fat $(3-6,23)$. This increase in insulin resistance causes more insulin to be secreted to maintain NGT. Individuals with islets of genetically abnormal pancreatic $\beta$ cells (individuals at risk of type 2 diabetes mellitus; progressor group individuals) have a limited insulin resistance compensation capacity. Age of onset and type 2 diabetes mellitus severity are determined by the balance between the compensation capacity of $\beta$ cells and the level of insulin resistance $(1,4,6)$.

With advancing age comes an increase in blood glucose and, consequently, $\mathrm{HbA}_{1 \mathrm{c}}$ levels. In the present study, both groups had similar values for each variable, although fasting blood glucose values were always higher in the progressor group. An elevated fasting blood glucose level has already been demonstrated to be one of the risk factors for type 2 diabetes mellitus, and is used in clinical practice as such $(5,6,22,32)$. Population studies have considered that elevated fasting insulinemia demonstrates insulin resistance (32). In our study, weight gain and central adiposity in both groups were not sufficient to elevate fasting plasma insulin levels. Furthermore, in our progressor group, the high basal blood glucose was not accompanied by increased plasma insulin, suggesting a deficiency in insulin secretion.

During the study period, the average age of the nonprogressors changed from the mid-30's to mid-40's, but the group was still relatively young. Thus, they maintained their plasma glucose and insulin curves associated with the OGTT. However, although the progressor group aged similarly, they presented a significant increase in blood glucose response and a reduction in early insulin response during the OGTT. The final insulinemic curve for the progressor group following oral glucose challenge showed a much later peak (at $90 \mathrm{~min}$ ) and much higher levels in the second hour than did the non-progressor group, but these insulin responses were inadequate to match the correspondingly elevated blood glucose values. These data suggest that defects in $\beta$ cell function occur early in the evolution towards type 2 diabetes mellitus, as seen in previous studies, including our own $(2,12,20,33,34)$.

The progressor group's drop in early insulin secretion over time suggests aggravation of the already deficient first-phase insulin secretion. Basal plasma insulin and OGTT insulin values for the progressor group did not suggest a drop in insulin sensitivity, which initially did not differ from that of the non-progressor group. Also, some individuals from both groups had participated in an earlier study (34) in which insulin secretion and action were analyzed by hyperglycemic clamp technique in IGT and NGT individuals, respectively. Reductions in first- and second-phase insulin secretion were verified without changes in insulin sensitivity index in IGT individuals who were well-paired with NGT individuals for gender, age, $\mathrm{BMI}$, and $\mathrm{W} / \mathrm{H}$ ratio. This result supports those from earlier studies $(25,30,33)$.

In conclusion, in our analyses comparing progressor and non-progressor groups, insulin resistance factors were present equally in both groups, suggesting that $\beta$ cell dysfunction was the risk factor or determinant of evolution for glucose intolerance (IGT or type 2 diabetes mellitus state). In Brazilian people, as in other populations $(1,10,35)$, careful and prospective study supports that $\beta$ cell secretion deficiency is the primary defect of type 2 diabetes mellitus. 


\section{References}

1. Gerich JE. Contributions of insulin-resistance and insulinsecretory defects to the pathogenesis of type 2 diabetes mellitus. Mayo Clin Proc 2003; 78: 447-456.

2. Del Guerra S, Lupi R, Marselli L, Masini M, Bugliani M, Sbrana S, et al. Functional and molecular defects of pancreatic islets in human type 2 diabetes. Diabetes 2005; 54: 727-735.

3. Weyer C, Bogardus C, Mott DM, Pratley RE. The natural history of insulin secretory dysfunction and insulin resistance in the pathogenesis of type 2 diabetes mellitus. J Clin Invest 1999; 104: 787-794.

4. Chen KW, Boyko EJ, Bergstrom RW, Leonetti DL, NewellMorris L, Wahl PW, et al. Earlier appearance of impaired insulin secretion than of visceral adiposity in the pathogenesis of NIDDM. 5-Year follow-up of initially nondiabetic Japanese-American men. Diabetes Care 1995; 18: 747-753.

5. Ferrannini E, Nannipieri M, Williams K, Gonzales C, Haffner SM, Stern MP. Mode of onset of type 2 diabetes from normal or impaired glucose tolerance. Diabetes 2004; 53: 160-165.

6. Lyssenko V, Almgren P, Anevski D, Perfekt R, Lahti K, Nissen $M$, et al. Predictors of and longitudinal changes in insulin sensitivity and secretion preceding onset of type 2 diabetes. Diabetes 2005; 54: 166-174.

7. Pimenta WP, Santos ML, Cruz NS, Aragon FF, Padovani CR, Gerich JE. Insulin secretion, insulin sensitivity, and hepatic insulin extraction in first-degree relatives of type 2 diabetic patients. Braz J Med Biol Res 2003; 36: 301-308.

8. Pimenta W, Korytkowski M, Mitrakou A, Jenssen T, YkiJarvinen $\mathrm{H}$, Evron $\mathrm{W}$, et al. Pancreatic beta-cell dysfunction as the primary genetic lesion in NIDDM. Evidence from studies in normal glucose-tolerant individuals with a firstdegree NIDDM relative. JAMA 1995; 273: 1855-1861.

9. Report of the Expert Committee on the Diagnosis and Classification of Diabetes Mellitus. Diabetes Care 1997; 20: 1183-1197.

10. Pratley RE, Weyer C. The role of impaired early insulin secretion in the pathogenesis of type II diabetes mellitus. Diabetologia 2001; 44: 929-945

11. Norman GR, Streiner DL. Biostatistics - The bare essentials. St. Louis: Mosby Year Book; 1994.

12. Mitrakou A, Kelley D, Mokan M, Veneman T, Pangburn T, Reilly $\mathrm{J}$, et al. Role of reduced suppression of glucose production and diminished early insulin release in impaired glucose tolerance. N Engl J Med 1992; 326: 22-29.

13. Kahn SE, Prigeon RL, McCulloch DK, Boyko EJ, Bergman $\mathrm{RN}$, Schwartz MW, et al. Quantification of the relationship between insulin sensitivity and beta-cell function in human subjects. Evidence for a hyperbolic function. Diabetes 1993; 42: $1663-1672$.

14. Chiasson JL, Rabasa-Lhoret R. Prevention of type 2 diabetes: insulin resistance and beta-cell function. Diabetes 2004; 53 (Suppl 3): S34-S38.

15. Yki-Jarvinen $\mathrm{H}$. Role of insulin resistance in the pathogenesis of NIDDM. Diabetologia 1995; 38: 1378-1388.

16. Bonora E, Micciolo R, Ghiatas AA, Lancaster JL, Alyassin A, Muggeo $M$, et al. Is it possible to derive a reliable estimate of human visceral and subcutaneous abdominal adi- pose tissue from simple anthropometric measurements? Metabolism 1995; 44: 1617-1625.

17. Gerich JE. The genetic basis of type 2 diabetes mellitus: impaired insulin secretion versus impaired insulin sensitivity. Endocr Rev 1998; 19: 491-503.

18. Xiang AH, Wang C, Peters RK, Trigo E, Kjos SL, Buchanan TA. Coordinate changes in plasma glucose and pancreatic beta-cell function in Latino women at high risk for type 2 diabetes. Diabetes 2006; 55: 1074-1079.

19. Ward WK, LaCava EC, Paquette TL, Beard JC, Wallum BJ, Porte D Jr. Disproportionate elevation of immunoreactive proinsulin in type 2 (non-insulin-dependent) diabetes mellitus and in experimental insulin resistance. Diabetologia 1987; 30: 698-702.

20. Del Prato $S$, Marchetti $P$. Beta- and alpha-cell dysfunction in type 2 diabetes. Horm Metab Res 2004; 36: 775-781.

21. LeRoith D. Beta-cell dysfunction and insulin resistance in type 2 diabetes: role of metabolic and genetic abnormalities. Am J Med 2002; 113 (Suppl 6A): 3S-11S.

22. Weyer C, Tataranni PA, Bogardus C, Pratley RE. Insulin resistance and insulin secretory dysfunction are independent predictors of worsening of glucose tolerance during each stage of type 2 diabetes development. Diabetes Care 2001; 24: 89-94.

23. Qiao Q, Lindstrom J, Valle TT, Tuomilehto J. Progression to clinically diagnosed and treated diabetes from impaired glucose tolerance and impaired fasting glycaemia. Diabet Med 2003; 20: 1027-1033.

24. Piche ME, Lemieux S, Perusse L, Weisnagel SJ. High normal 2-hour plasma glucose is associated with insulin sensitivity and secretion that may predispose to type 2 diabetes. Diabetologia 2005; 48: 732-740.

25. Byrne MM, Sturis J, Sobel RJ, Polonsky KS. Elevated plasma glucose $2 \mathrm{~h}$ postchallenge predicts defects in beta-cell function. Am J Physiol 1996; 270: E572-E579.

26. Suzuki H, Fukushima M, Usami M, Ikeda M, Taniguchi A, Nakai $Y$, et al. Factors responsible for development from normal glucose tolerance to isolated postchallenge hyperglycemia. Diabetes Care 2003; 26: 1211-1215.

27. Calles-Escandon J, Robbins DC. Loss of early phase of insulin release in humans impairs glucose tolerance and blunts thermic effect of glucose. Diabetes 1987; 36: 11671172.

28. Ryan EA, Imes S, Liu D, McManus R, Finegood DT, Polonsky KS, et al. Defects in insulin secretion and action in women with a history of gestational diabetes. Diabetes 1995; 44: 506-512.

29. Silverman BL, Metzger BE, Cho NH, Loeb CA. Impaired glucose tolerance in adolescent offspring of diabetic mothers. Relationship to fetal hyperinsulinism. Diabetes Care 1995; 18: 611-617.

30. Vaag A, Henriksen JE, Madsbad S, Holm N, Beck-Nielsen $\mathrm{H}$. Insulin secretion, insulin action, and hepatic glucose production in identical twins discordant for non-insulin-dependent diabetes mellitus. J Clin Invest 1995; 95: 690-698.

31. van Haeften TW, Dubbeldam S, Zonderland ML, Erkelens DW. Insulin secretion in normal glucose-tolerant relatives of type 2 diabetic subjects. Assessments using hyperglycemic 
glucose clamps and oral glucose tolerance tests. Diabetes Care 1998; 21: 278-282.

32. Haffner SM, Miettinen H, Gaskill SP, Stern MP. Decreased insulin action and insulin secretion predict the development of impaired glucose tolerance. Diabetologia 1996; 39: 12011207.

33. Pimenta W, Mitrakou A, Jensen T, Yki-Jarvinen H, Daily G, Gerich J. Insulin secretion and insulin sensitivity in people with impaired glucose tolerance. Diabet Med 1996; 13: S33-
S36.

34. Pimenta WP, Santos ML, Cruz NS, Aragon FF, Padovani $\mathrm{CR}$, Gerich JE. Brazilian individuals with impaired glucose tolerance are characterized by impaired insulin secretion. Diabetes Metab 2002; 28: 468-476.

35. Abdul-Ghani MA, Tripathy D, DeFronzo RA. Contributions of beta-cell dysfunction and insulin resistance to the pathogenesis of impaired glucose tolerance and impaired fasting glucose. Diabetes Care 2006; 29: 1130-1139. 